\title{
A new perspective in liver fibrosis: Etiology removal does not cause regression of liver fibrosis
}

Suzan Bakr Abdu

*Correspondence: suzanabdu3@gmail.com

CrossMark

$\leftarrow$ Click for updates

Associate Professor of Cell Biology and Histology, Faculty of Science, King Abdulaziz University, P.O. Box 80200, Jeddah, Saudi Arabia.

\begin{abstract}
Liver fibrosis is a wound healing process involves inflammation, extracellular matrix deposition, and vascularization. It results from chronic injuries and often progresses to cirrhosis. However, many studies proposed that fibrosis regression occurred when the underlying etiology is removed. Thus, this study aimed to investigate the histological events of hepatic fibrosis regression after removing the causative agent. Three groups of rats were assigned, control, dimethylnitrosamine (DMN) to induce fibrosis $(10 \mathrm{mg} / \mathrm{kg} /$ day, 3 days/week for 3 weeks), and DMN cessation group to monitor fibrosis regression(at the fourth week). Statistical analysis was performed by one-way analysis of variance (ANOVA). DMN administration demonstrated a significant decrease of body weight, as well as a marked increase of inflammatory infiltrate, collagen fibers deposition, bile ducts proliferation, new blood vessels formation, and necrosis. However, cessation of DMN caused a marked alleviation of the histopathological findings including, body weight, inflammatory infiltrates, bile ducts proliferation as well as necrosis. On the other hand, vascular remodeling continued through collagen fibers deposition and branching to the adjacent blood vessels, substituting the parenchyma with scar tissue. Subsequently resorbed, and displayed large luminal vascular structures which called angiogenesis. In conclusion, removal of the etiology clearly declined the necro-inflammatory level along with ducts proliferation. However, fibrosis had progressed to cirrhosis which may correlate to angiogenesis.
\end{abstract}

Keywords: Liver fibrosis, early cirrhosis, angiogenesis, vascular endothelial cells

\section{Introduction}

Liver fibrosis is a significant health problem results from dysregulation of normal wound healing, includes inflammation, activation of myofibroblasts, and deposition of extracellular matrix (ECM). Chronic liver injury results in death of hepatocytes and formation of apoptotic bodies, which in turn, release factors that recruit inflammatory cells (neutrophils, monocytes, macrophages, and lymphocytes) to the injured liver. Several studies have revealed that hepatic fibrosis can reverse and regress upon cessation of liver injury. Regression of liver fibrosis is accompanied by the disappearance of fibrogenic myofibroblasts followed by resorption of the fibrous scar [1].

After acute injury, the liver can restore its complete mass and original architecture in a fairly short time even when a large fraction of the organ is destroyed. In contrast, chronic liver injury induced by repetitive tissue damage,results in impaired regenerative capacity marked by altered inflammatory infiltrate and a chronic wound healing response $[2,3]$. The response to chronic injury also includes necrosis and/or apoptosis of parenchymal cells and their substitution by ECM. Furthermore, the wound healing process becomes pathogenic if it progressively replaces parenchyma with scar tissue and destroys the liver vascular architecture, eventually causing organ dysfunction. Studies suggested therapies for chronic liver disease by removing the causative agent [4]. Liver fibrosis is a dynamic process that can be regulated either by pausing progression and/or promoting resolution. This involves a complicated process concerning parenchymal and non-parenchymal liver cells, as well as infiltrating immune cells. Chronic hepatocyte death via apoptosis or necrosis is a critical step. Cell death induces activation of inflammatory and pro-fibrogenic pathways in non-parenchymal cells and infiltrating immune cells, which 
trigger fibrosis progression, but may contribute to fibrosis resolution $[\mathbf{2}, \mathbf{3}, \mathbf{5}]$. Resolution of fibrosis refers to hepatic stellate cell (HSC) apoptosis, senescence, or quiescence [6]. Hepatocytes death leads to the release of cellular contents (DNA and damage-associated molecular patterns (DAMPs) and reactive oxygen species (ROS) that activate Kupffer cells $[7,8]$. Oxidative stress contributes to the overexpression of critical genes related to ECM remodeling and inflammation as well as to all fibrogenic disorders, which results in chronic tissue damage [9]. Hepatic macrophages (Kupffer cells) coordinate the regenerative response during acute injury. However, drive fibrosis progression during chronic injury. Interestingly, macrophages are the fuel and brake of liver fibrosis progression and resolution. In addition, hepatic macrophages drive HSC activation [10].

Angiogenesis is the formation of new vessels from preexisting vessels caused by diminished oxygen transport to the parenchyma, which takes place in several organs during growth and repair of injured tissues. Angiogenesis is a fundamental part of tumor progression and contributes to the pathogenesis of different inflammatory, fibroproliferative and ischemic diseases [11]. However, recent data ofchronic liver diseases (CLDs) have revealed that angiogenesis might contribute to the progression of fibrosis during the wound healing process in chronic liver damage $[12,13]$.

This study aims to provide an overview of the histopathological events of liver fibrosis progression and/or regression in rat model, during DMN administration and elimination. The clarification of the mechanisms underlying these events is fundamentally important for establishing antifibrotic therapies.

\section{Materials and methods Chemicals}

$\mathrm{N}$-Nitrosodimethylamine (dimethyl n-nitrosamine; DMN) Cat no: $591068 \mathrm{~N}$ Nitrosodimethylamine-d6, 98 atom\% d sigma (St. Louis, MO, USA).

\section{Experimental Animals and Design}

Twenty eight (28) male albino Wistar rats weighing (90-116 g) were obtained from the animal house of King Fahd Research Medical Center at King Abdulaziz University, Jeddah, Saudi Arabia. Animals were housed in a well-ventilated temperature controlled room at $22 \pm 23^{\circ} \mathrm{C}$ with 12 hours light and dark cycles. Food consisted of standard laboratory rat chow with free access to water, and care was taken to avoid all stressful conditions. Institutional Animal Ethical Committee permission was obtained before performing the experiments.

Rats were divided into three groups. The control $(n=14)$ received saline administered orally via gastric intubation. Seven rats were sacrificed after three weeks, 21 days. The rest $(n=7)$ continued treatment and sacrificed after one more week, 28 days. The DMN ( $n=7)$ administered at a dose of 10 $\mathrm{mg} / \mathrm{kg} / \mathrm{day}(10 \mu \mathrm{l} \mathrm{DMN}$ diluted to $1 \mathrm{ml}$ with $0.15 \mathrm{M}$ sterile $\mathrm{Na}$ $\mathrm{Cl}$ ) via intraperitoneal injection in the first three days of each week for three weeks $[\mathbf{1 4 , 1 5}]$ to induce liver fibrosis. Rats in group $3(n=7)$ received the same amount of DMN for three weeks. On the fourth week received normal saline. Animals were weighed at the beginning of each week.

\section{Statistical analysis}

Values for body and liver weights are expressed as mean value \pm SD. Statistical analysis was performed by one-way analysis of variance (ANOVA) using SPSS 23.0 software (SPSS Inc., USA). Statistical significance was estimated by one way ANOVA. $P<0.05$ was considered statistically significant.

\section{Histological studies}

Animals were sacrificed after 21 (control and DMN) and 28 days(control and DMN cessation) under ether anesthesia by cervical dislocation. The livers were weighed, and fixed in $10 \%$ neutral buffered formalin for histological study by light microscopy.

\section{Results}

The average body weight of the DMN treated group after 21 days was significantly low compared to the control. However, this significance decreased after removal of DMN. On the other hand, the relative liver weight of DMN group was higher than the control after 21 days(DMN group), but lower than the control after DMN cessation (Table 1).

Table 1. Effect of DMN administration and cessation on body and liver weights of rats.

\begin{tabular}{|c|c|c|c|}
\hline $\begin{array}{l}\text { Body weight } \\
\text { (g) }\end{array}$ & $\begin{array}{l}\text { Control } \\
\text { G1 }\end{array}$ & $\begin{array}{l}\text { DMN } \\
\text { Administration } \\
\text { (G2) }\end{array}$ & $\begin{array}{l}\text { DMN } \\
\text { Cessation } \\
\text { (G3) }\end{array}$ \\
\hline Day 0 & $99.80 \pm 3.83$ & $110.80 \pm 4.96$ & -- \\
\hline Day 7 & $120.60 \pm 12.72$ & $121.40 \pm 8.96$ & -- \\
\hline Day 14 & $153.40 \pm 9.71$ & $148.80 \pm 12.67$ & -- \\
\hline Day 21 & $188.20 \pm 18.55$ & $160.60 \pm 8.38^{*}$ & -- \\
\hline Day 28 & $206.33 \pm 32.88$ & -- & $209.25 \pm 2.21$ \\
\hline $\begin{array}{l}\text { Ratio of total } \\
\text { increase in body } \\
\text { weight ( } 21 \text { days) }\end{array}$ & $88.5 \%$ & $44.9 \%^{*}$ & -- \\
\hline $\begin{array}{l}\text { Ratio of total } \\
\text { increase in body } \\
\text { weight ( } 28 \text { days) }\end{array}$ & $106.74 \%$ & -- & $88.85 \%$ \\
\hline Liver weight Day 21 & $9.81 \pm .47$ & $9.32 \pm 1.20$ & -- \\
\hline Liver weight Day 28 & $10.31 \pm .82$ & -- & $9.35 \pm 2.21$ \\
\hline $\begin{array}{l}\text { Relative Liver } \\
\text { weight }(21 \mathrm{~d})\end{array}$ & $5.2 \%$ & $5.8 \%$ & -- \\
\hline $\begin{array}{l}\text { Relative Liver } \\
\text { weight ( } 28 \mathrm{~d})\end{array}$ & $5 \%$ & -- & $4.47 \%$ \\
\hline
\end{tabular}

Results are presented as mean \pm SEMP $\leq 0.05$. ${ }^{\star}$ Indicates a significant difference between rats treated with DMN and control group.

Histological sections obtained from the liver tissues of all groups were examined using light microscopy. The control liver showed normal liver architecture (Figures 1A, 2A and 3A). 


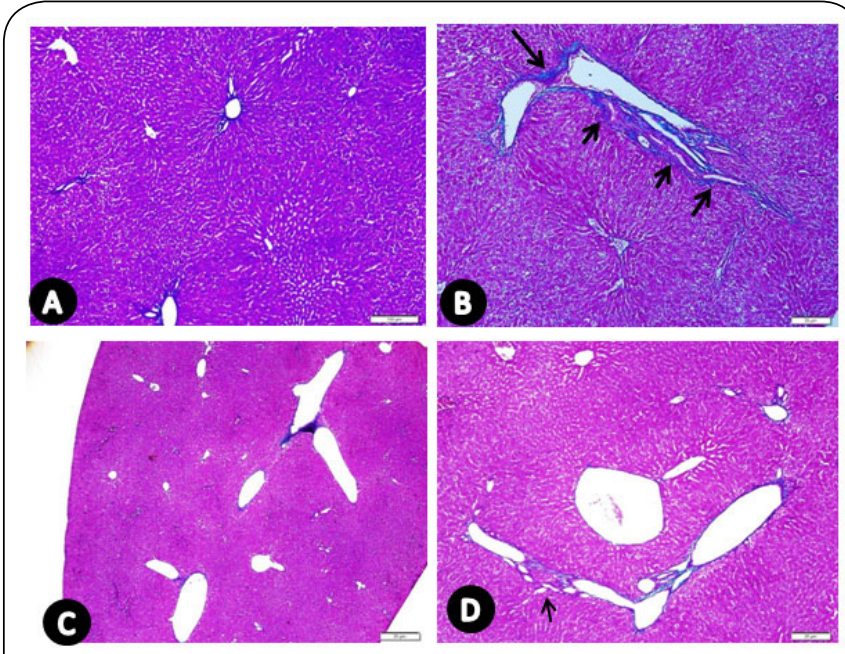

Figure 1. Collagen fibers in liver sectionsof rat.

(A) control, normal histology with typical lobular architecture (B). DMN, disrupted vascular architecture with vasodilation and collagen deposition around the portal area. Sprouting and budding of vascular structures with bundles of collagen fibers surrounding portal areas displaying bridging fibrosis (long arrow). Bile ducts proliferation (arrows). (C\&D) DMN cessation, dilatation of central and portal veins with fibrous septa link portal tracts creating large luminal tubules, ECM remodeling (arrow). Note, collagenous septa invading the liver parenchyma reaching to the adjacent veins. (MTS. X10 A, B, D; X4C).

However, administration of DMN for 21 days induced severe histopathological changes in the liver tissue. The lobular and vascular architecture was destructed and the liver organization was distorted. Masson's trichrome stained sections demonstrated well developed portal fibrosis as well as severe disruption of vascular architecture. Portal veins were dilated and branched into the adjacent parenchyma. Septa of fibrous tissue joined portal tracts to portal tracts. The general pattern of the liver architecture was irregular, with bridging fibrosis and extensive proliferation of the bile ducts and ductules (Figure 1B). H\&E staining demonstrated vascular thrombosis in many portal veins as well as focal congestion with marked dilatation and deformation of portal veins.Venous walls were thickened to the point where it resembled an artery. Early cirrhosis was noticed in many areas. Portal tracts become progressively expanded and infiltrated by lymphocytes and collagenous septa displaying bridging necrosis and bridging fibrosis (Figure 2B). Incomplete septal cirrhosis characterized by delicate and fragmented or blind ending fibrous septa associated with destructed vessels was evident. Necrosis commonly occurred in the periportal areas, the cords of hepatocytes were very irregular (Figure 2D), large groups of hepatocytes were degenerated and greatly swollen. Subsequently, they become necrotic and lysed (Figure 3B).

Up on cessation of DMN for a week, histological examination of this group revealed considerably altered liver architecture

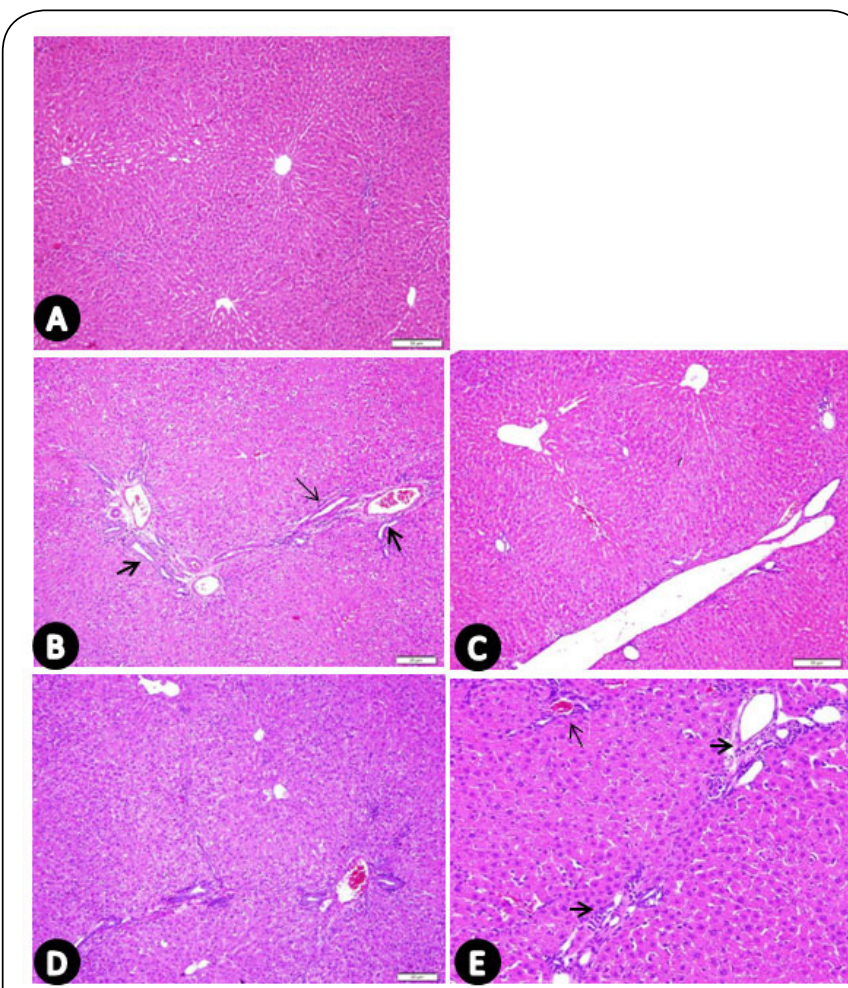

Figure 2. Vascularization of fibrotic liver sections of rat. (A) control. (B). DMN, early cirrhosis, bile ducts proliferation (thick arrows), with thickening of portal vein wall. Note muscular hypertrophy of hepatic vein branch (thin arrow). (C). DMN cessation, Endothelial cell proliferation and lumen formation. Distortion of vascular architecture displaying angiogenesis with large luminal thin walled vascular structures. (D). DMN extended inflammatory infiltrates. (E). DMN cessation. Anoticeble reduction of inflammatory infiltrate and necrosis. Segments of bile ducts have been destroyed and almost no bile ducts remain in the portal tracts. Note. Portal tracts remnants (arrows), and hemorrhagic portal vein (thin arrow). Hepatocytes appear comparatively normal. (H\&E, X10 A, B, C, D; X20 E).

with dilated and linked vascular structures extended through the liver tissue. Trichrome staining exhibited collagenous septa migrated between vascular structures destroying the liver's parenchyma reaching to the adjacent vessels (Figures $1 \mathrm{C}$ and 1D). Luminal thin wall vessels extended through the liver tissue were clearly evident. Necrosis, inflammatory infiltrates as well as bile ducts proliferation all were markedly reduced after cessation of DMN compared to DMN administration. Portal and central veins were indistinguishable due to the obliteration of the bile ducts. Large bile ducts were no longer visible and were destroyed or obliterated (Figures $2 \mathrm{C}$ and 2E). Mild atrophy of hepatic cords around the central vein resulted in widening and dilation of the sinusoids. Increased number of Kupffer cells as well as hepatocyte's apoptosis was clearly noticed in this group (Figures 3C and 3D). Thrombosis and sinusoidal congestion was commonly reduced compared to DMN treatment. 


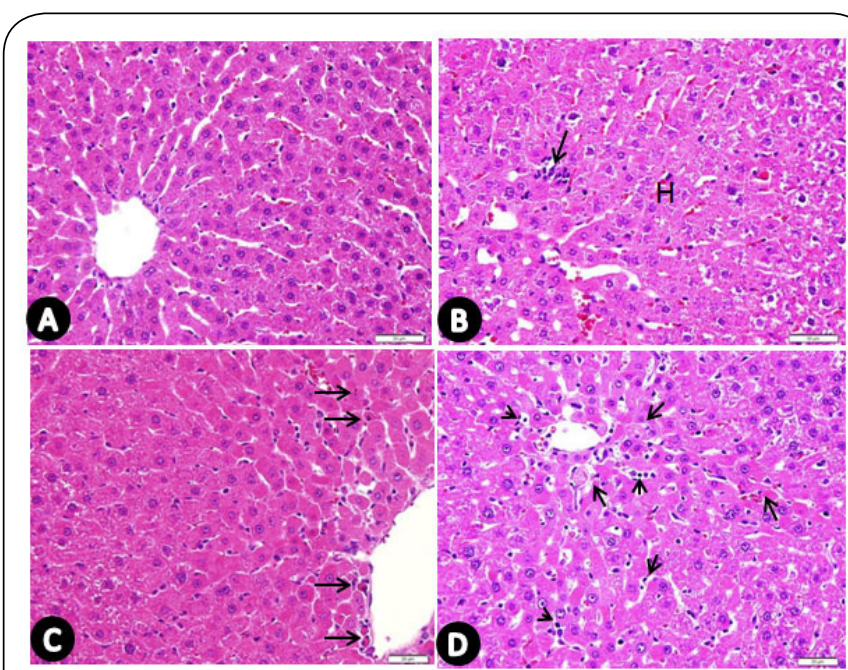

Figure 3. Apoptosis and Kupffer cell recruitment in liver sections of rat.

(A). Control. (B), DMN, lymphocytic inflammation and necrosis (arrow), with congested sinusoids, and damaged hepatocytes (H). (C). DMN cessation, increased apoptosis (arrows). (D). DMN cessation, sinusoidal dilatation and Kupffer cell recruitments (arrows). (H\&E. X40).

\section{Discussion}

Liver fibrosis is a reversible wound healing response to acute or chronic cellular injury. During acute injury, the changes in liver architecture are reversible. However, with chronic injury, there is progressive substitution of the liver parenchyma by scar tissue. Although the liver has a remarkable capacity to regenerate, fibrosis progress slowly to cirrhosis [6]. In the present study, a kind of communication and signaling between cells was noticed though the disappearance of the nuclei and eosinophilia of the cytoplasm may be as a result of a smooth muscle actin expression, Subsequently, collagen fibers deposit and extend to the adjacent veins. Afterwards, resorption of the scar occurs and vascular structures are linked together. The architecture of the liver was disrupted. The present study revealed a marked increase in extended luminal vascular structures after cessation of DMN. Thus, distorting the liver vascular architecture and eventually lead to organ dysfunction.

These vascular structures may be appeared due to a change in the fenestrations of the endothelial cells as a result of ROS from the DMN which is capable of transforming endothelial cells into a vascular type. In chronic hepatitis and cirrhosis especially primary biliary cirrhosis (PBC), with the formation of a true basement membrane liver sinusoidal endothelial cells (LSECs) frequently undergo transformation into continuous or vascular type endothelial cells possessing a basement membrane and no fenestrae in patients with biliary cirrhosis [16-19]. The transformation of LSECs is important for disease progression and explains some of the pathological hallmarks of the cirrhotic liver. Transforming LSECs into a vascular type may play an important role in the development of hepatocel- lular failure and portal hypertension [19].

The unique arrangement of the normal sinusoidal endothelium is likely to facilitate the large exchanges that take place between hepatocytes and the blood. It is known that the formation of basement membrane and changes in LSECs will interfere with the bidirectional exchange of molecules and therefore have harmful effects on liver function, such as decreased sinusoidal compliance with increased resistance to blood flow, and may contribute to development of portal hypertension in PBC. Babbs et al. [18] have discussed other consequences that may result from these changes, such as development of cirrhosis by causing ischemic atrophy of hepatocytes, thereby leading to increased fibrogenesis and compensatory hypertrophy of neighboring hepatocytes.

Changes in venous blood flow are thought to occur as a complication of fibrosis and vascular lesions. A recent study by Stefan G. Hübscher [20] proposed endothelial mesenchymal transition as a mechanism for occlusion of small portal vein in portal hypertension. Furthermore, the development of shunt vessels is a compensatory way of the obliteration of small portal vein branches. Foci of sinusoidal dilatation with variable congestion were resulted from parenchymal hyperfusion which developed as a result of shunt vessels [21].

The present study disagrees with the previous studies that reported upon removal of the etiological source of the chronic injury, regression of liver fibrosis is associated with decreased cytokines and ECM production, increased collagenase activity, disappearance of collagen producing myofibroblast population and resorption of the fibrous scar $[2,22,23]$. The present study has clearly revealed a decrease in the extent of necro-inflammation, but no regression in fibrosis upon removal of the etiology. This is in accordance with the study of Hézode et al. [24]. Another perspective agrees that control and clearance of the underlying causative etiology can slow down fibrosis progression and lead to fibrosis regression [25]. In other words, myofibroblasts may undergo apoptosis and inactivation when the underlying causative etiologies are removed.

Previous studies has correlated fibrosis and angiogenesis and contributed the progression of fibrosis during the wound healing process in chronic liver damage to angiogenesis $[12,13]$. Many recent studies correlate angiogenesis with the progression of fibrosis in CLDs at the-end point of cirrhosis. In other words, the persistence of tissue damage and inflammation perpetuates the activation of endothelial cells (ECs) resulting in the increase of vascular permeability and promoting chemokine-mediated recruitment of inflammatory cells. These cells can produce angiogenic cytokines and growth factors that stimulate the proliferation and migration of ECs that are necessary for the formation of new vessels $[26,27]$. Sprouting and branching of endothelial cells (ECs)is the first step of angiogenesis. In quiescent state ECs adhere to each other and to extracellular matrix (ECM) through junctions to provide tightness to establish a barrier, and allow intercellular 
communications. Stimulus increases vascular permeability results in leakage from vessels as well as influences branching of new vessels, deposition of ECM and formation of basement membrane $[\mathbf{2 8 , 2 9 ]}$. Continuous capillarization of sinusoids occurs and causes the loss of specific endothelial fenestrations. This process together with the accumulation of fibrotic tissue provokes vascular resistance and diminishes the transport of oxygen to the parenchyma (hypoxia) leading to up-regulation of pro-angiogenic mechanisms via hypoxia [30].

Previous study explained the existence of activated Kupffer cells that reside in hepatic sinusoids as seen in the present study, may contribute to angiogenesis by their ability to release of ROS and platelet-activating factor. An increase of ROS and nitrogen species may induce new vessel formation by the stimulation of TNF, NO, HIF-1 and VEGF expressions [31].

\section{Conclusion}

Although the inflammatory infiltrates and necrosis were markedly decreased by the removal of the causative agent, but vascular remodeling or, angiogenesis, was increased implicating no fibrosis regression. Angiogenesis may contribute to the progression of fibrosis.

\section{Competing interests}

The author declares that she has no competing interests.

\section{Acknowledgement}

The author thanks the light microscopy unit at King Fahd Medical Center of King Abdulaziz University, Jeddah, Saudi Arabia.

Publication history

EIC: Gaetano Giuseppe Magro, University of Catania, Italy. Received: 05-Feb-2018 Final Revised: 18-Mar-2018

Accepted: 25-Mar-2018 Published: 08-Apr-2018

\section{References}

1. Xu J, Liu X, Koyama Y, Wang P, Lan T, Kim IG, Kim IH, Ma HY and Kisseleva T. The types of hepatic myofibroblasts contributing to liver fibrosis of different etiologies. Front Pharmacol. 2014; 5:167. | Article | PubMed Abstract | PubMed FullText

2. Bataller R and Brenner DA. Liver fibrosis. J Clin Invest. 2005; 115:209-18. | Article | PubMed Abstract | PubMed FullText

3. Lee YA, Wallace MC and Friedman SL. Pathobiology of liver fibrosis: a translational success story. Gut. 2015; 64:830-41. | Article | PubMed Abstract | PubMed FullText

4. Trautwein C, Friedman SL, Schuppan D and Pinzani M. Hepatic fibrosis: Concept to treatment. J Hepatol. 2015; 62:S15-24. | $\underline{\text { Article I PubMed }}$

5. Pinzani $M$ and Macias-Barragan J. Update on the pathophysiology of liver fibrosis. Expert Rev Gastroenterol Hepatol. 2010; 4:459-72. | Article I PubMed

6. Lee UE and Friedman SL. Mechanisms of hepatic fibrogenesis. Best Pract Res Clin Gastroenterol. 2011; 25:195-206. | Article | PubMed Abstract | PubMed FullText

7. Seki E, De Minicis S, Osterreicher CH, Kluwe J, Osawa Y, Brenner DA and Schwabe RF. TLR4 enhances TGF-beta signaling and hepatic fibrosis. Nat Med. 2007; 13:1324-32. | Article I PubMed

8. Liu C, Chen X, Yang L, Kisseleva T, Brenner DA and Seki E. Transcriptional repression of the transforming growth factor beta (TGF-beta)
Pseudoreceptor BMP and activin membrane-bound inhibitor (BAMBI) by Nuclear Factor kappaB (NF-kappaB) p50 enhances TGF-beta signaling in hepatic stellate cells. J Biol Chem. 2014; 289:7082-91. | Article | PubMed Abstract | PubMed FullText

9. Novo $E$ and Parola M. Redox mechanisms in hepatic chronic wound healing and fibrogenesis. Fibrogenesis Tissue Repair. 2008; 1:5. | Article | PubMed Abstract | PubMed FullText

10. Pellicoro A, Ramachandran P, Iredale JP and Fallowfield JA. Liver fibrosis and repair: immune regulation of wound healing in a solid organ. Nat Rev Immunol. 2014; 14:181-94. | Article | PubMed

11. Carmeliet $P$ and Jain RK. Molecular mechanisms and clinical applications of angiogenesis. Nature. 2011; 473:298-307. | Article | PubMed Abstract I PubMed FullText

12. Valfre di Bonzo L, Novo E, Cannito S, Busletta C, Paternostro C, Povero D and Parola M. Angiogenesis and liver fibrogenesis. Histol Histopathol. 2009; 24:1323-41. I Article I PubMed

13. Ciupinska-Kajor M, Hartleb M, Kajor M, Kukla M, Wylezol M, Lange D and Liszka L. Hepatic angiogenesis and fibrosis are common features in morbidly obese patients. Hepatol Int. 2013; 7:233-40. | Article | PubMed Abstract | PubMed FullText

14. Jezequel AM, Mancini R, Rinaldesi ML, Ballardini G, Fallani M, Bianchi $F$ and Orlandi F. Dimethylnitrosamine-induced cirrhosis. Evidence for an immunological mechanism. J Hepatol. 1989; 8:42-52. | $\underline{\text { Article | PubMed }}$

15. Lee ES, Lee HE, Shin JY, Yoon S and Moon JO. The flavonoid quercetin inhibits dimethylnitrosamine-induced liver damage in rats. J Pharm Pharmacol. 2003; 55:1169-74. | Article | PubMed

16. Fukuda $\mathrm{Y}, \mathrm{Nagura} \mathrm{H}$, Imoto $\mathrm{M}$ and Koyama $\mathrm{Y}$. Immunohistochemical studies on structural changes of the hepatic lobules in chronic liver diseases. Am J Gastroenterol. 1986; 81:1149-55. | PubMed

17. Petrovic LM, Burroughs A and Scheuer PJ. Hepatic sinusoidal endothelium: Ulex lectin binding. Histopathology. 1989; 14:233-43. | Article I PubMed

18. Babbs C, Haboubi NY, Mellor JM, Smith A, Rowan BP and Warnes TW. Endothelial cell transformation in primary biliary cirrhosis: a morphological and biochemical study. Hepatology. 1990; 11:723-9. I Article I PubMed

19. Xu B, Broome U, Uzunel M, Nava S, Ge X, Kumagai-Braesch M, Hultenby $\mathrm{K}$, Christensson B, Ericzon BG, Holgersson J and Sumitran-Holgersson S. Capillarization of hepatic sinusoid by liver endothelial cell-reactive autoantibodies in patients with cirrhosis and chronic hepatitis. Am J Pathol. 2003; 163:1275-89. | Article I PubMed Abstract I PubMed FullText

20. Hübscher SG. Pathology of non-cirrhotic portal hypertension and incomplete septal cirrhosis. Diagnostic Histopathology. 2011; 17:530538.

21. Ludwig J, Hashimoto $E$, Obata $H$ and Baldus WP. Idiopathic portal hypertension; a histopathological study of $\mathbf{2 6}$ Japanese cases. Histopathology. 1993; 22:227-34. | Article | PubMed

22. Iredale JP, Benyon RC, Pickering J, McCullen M, Northrop M, Pawley $S$, Hovell $C$ and Arthur MJ. Mechanisms of spontaneous resolution of rat liver fibrosis. Hepatic stellate cell apoptosis and reduced hepatic expression of metalloproteinase inhibitors. J Clin Invest. 1998; 102:53849. | Article | PubMed Abstract | PubMed FullText

23. Kisseleva T, Cong M, Paik Y, Scholten D, Jiang C, Benner C, Iwaisako K, Moore-Morris T, Scott B, Tsukamoto H, Evans SM, Dillmann W, Glass CK and Brenner DA. Myofibroblasts revert to an inactive phenotype during regression of liver fibrosis. Proc Natl Acad Sci U S A. 2012; 109:9448-53. | Article | PubMed Abstract | PubMed FullText

24. Hezode C, Castera L, Roudot-Thoraval F, Bouvier-Alias M, Rosa I, Roulot $D$, Leroy V, Mallat A and Pawlotsky JM. Liver stiffness diminishes with antiviral response in chronic hepatitis C. Aliment Pharmacol Ther. 2011; 34:656-63. I Article I PubMed

25. Koyama Y, Xu J, Liu X and Brenner DA. New Developments on the Treatment of Liver Fibrosis. Dig Dis. 2016; 34:589-96. | Article | PubMed Abstract I PubMed FullText

26. Bruno A, Pagani A, Pulze L, Albini A, Dallaglio K, Noonan DM and Mortara 
L. Orchestration of angiogenesis by immune cells. Front Oncol. 2014;

4:131. | Article | PubMed Abstract | PubMed FullText

27. Tecchio $C$ and Cassatella MA. Neutrophil-derived cytokines involved in physiological and pathological angiogenesis, in Angiogenesis, Lymphangiogenesis and Clinical Implications. Karger Publishers. 2014; 123-137.

28. Lampugnani MG. Endothelial adherens junctions and the actin cytoskeleton: an 'infinity net'? J Biol. 2010; 9:16. | Article | PubMed Abstract | PubMed FullText

29. Elpek GO. Angiogenesis and liver fibrosis. World J Hepatol. 2015; 7:37791. | Article | PubMed Abstract | PubMed FullText

30. Kukla M. Angiogenesis: a phenomenon which aggravates chronic liver disease progression. Hepatol Int. 2013; 7:4-12. | Article | PubMed

31. Coulon S, Heindryckx F, Geerts A, Van Steenkiste C, Colle I and Van Vlierberghe H. Angiogenesis in chronic liver disease and its complications. Liver Int. 2011; 31:146-62. | Article | PubMed

\section{Citation:}

Abdu SB. A new perspective in liver fibrosis: Etiology removal does not cause regression of liver fibrosis.

J Histol Histopathol. 2018; 5:6.

http://dx.doi.org/10.7243/2055-091X-5-6 